\title{
The Determination of main obstacles for the developing of high-quality documentation during EIA process on Natura 2000 sites
}

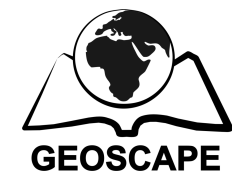

\author{
Zuzana Michalcová ${ }^{1 *}$ - Peter Baus ${ }^{2}$ \\ ${ }^{1}$ Department of Landscape Ecology, Faculty of Natural Sciences \\ Comenius University \\ Mlynska dolina, 84215 Bratislava, Slovakia \\ * zuzana.michalcova@gmail.com \\ ${ }^{2}$ Institute of Forest Ecology, Slovak Academy of Sciences, \\ Ludovíta Štúra 2, 960 53, Zvolen, Slovakia
}

\begin{abstract}
The issues of protection and management of biodiversity has become one of main environmental policy tasks in Europe and elsewhere. As an application of precautionary principles the EU member states are required to assess projects and plans which alone or in combination with other plans or projects are likely to have significant negative effects on Natura 2000 sites. Several EU provisions set out the obligations for such assessment (the Birds and Habitat Directives, EIA and SEA Directives). One of the key steps in the assessment process is to carry out the EIS (Environmental Impact Statement) - the final outcome of the assessment. If there is possibility of significant negative effects on Natura 2000 sites, the result of the process also has to be a part of EIS. The main goal of this study was to find out, what are the practitioners' opinions and attitudes on the quality of EIS in Slovakia, especially in the case when the assessment process is related to Natura 2000 sites. Because it often involves practitioners from a very wide range of disciplinary and professional backgrounds, the contribution tries to show to what extent does the professional background or practitioners working positions influence their perception of EIS quality.
\end{abstract}

Key words: EIA; Natura 2000; quality of EIS; questionnaire

Received: 15 Nov 2012 - Revised form: 2 Jan 2014 - Accepted: 7 Jan 2014

\section{Introduction}

Many scientists see EIA as an effective tool for environmental management (Ortolano and Shepard 1995; Snell and Cowell 2006; Samarakoon and Rowan 2008; Pavličková, Kozová et al. 2009a; Toro et al. 2010). We can say that EIA is an decision making tool with many purposes, but generally the main idea of this process is to identify the possible environmental consequences of planned projects in advance and try to find means to prevent negative impacts of development already in the planning phase.

One of key steps in EIA is to carry out an EIS (Environmental Impact Statement). The EIS is the final outcome of EIA process and it should include all the necessary environmental information related to a project and decision-making. The EIS is considered (Wood 2003) as a heart of the whole EIA process and Pinho et al. (2007) claim that EIS is the most important door, through which the scientific knowledge is transferring into the EIA process.

The quality of EIS as one of the most important factors - because of its close interconnection with decision-making process - is considered as a main tool for effective EIA process (Morrison-Saunders et al. 2001; Pavličková et al. 2009b; Jalava et al. 2010; Pölönen et al. 2011).

The issues of protection and management of biodiversity has become one of main environmental policy tasks in Europe and elsewhere. As an application of precautionary principles the EU member states are required to assess projects and plans which alone or in combination with other plans or projects are likely to have significant negative effects on Natura 2000 sites. Several EU provisions set out 
the obligations for such assessment (the Birds and Habitate Directives, EIA and SEA Directives).

The Habitats Regulations require to carry out appropriate assessments in certain circumstances where a plan or project affects a Natura (European) site. Habitats Regulations Appraisal (HRA) refers to the whole process, including the appropriate assessment step. Appropriate assessment (AA) is required when a plan or project affecting a Natura site.

This applies to any plan or project which has the potential to affect a Natura site, no matter how far away from that site. An appropriate assessment should focus exclusively on the qualifying interests of the Natura site affected and must consider any impacts on the conservation objectives of the site. It should also be based on, and supported by evidence that is capable of standing up to scientific scrutiny.

Appraisal of plans and projects under the Habitats Regulations is not the same as Environmental Impact Assessment (EIA) or Strategic Environmental Assessment (SEA). Some of the terms used in all three procedures are similar, but the steps and tests are very different.

The requirements of the Habitats Directive in respect of plans and projects are similar in many respects to Environmental Impact Assessment (EIA) of projects, and Strategic Environmental Assessment (SEA) of plans and programmes. However, the focus of AA is targeted specifically on Natura 2000 sites and their conservation objectives. Article 6(3) and 6(4) of the Habitats Directive place strict legal obligations on Member States, with the outcomes of AA fundamentally affecting the decisions that may lawfully be made.

In case of EIA where there is a possibility of significant negative effects on Natura 2000 sites, the result of AA process also has to be part of EIS. However, the assessments required by Article 6 of Habitats Regulations should be clearly distinguishable and identified within an environmental statement or reported separately.

There are few effective methods for ensuring efficient implementation of EIA process however the audit of documented outputs of the process is one of the most important. There are more forms how to do that - using checklists and review criteria is a useful way how to test the quality of documentation (EIS), to determine if they are fit to purpose and if the information meets the requirements.

But from this type of audit we cannot find out what practitioners opinions are, how their perceptions of EIS quality look like, and what they perceive as the main problems (dealing with quality of EIS).

Therefore the main goal of this study was to find out, what are the practitioners opinions and attitudes on the quality of EIS in Slovakia, especially in the case when the process EIA deals with Natura 2000 sites. The results obtained by this type of survey, could be very helpful for the determination of the main problems appearing during the EIS preparation. The determination of these problems is very important for their consequential minimalization or elimination.

The process of EIA often involves practitioners from a very wide range of disciplinary and professional backgrounds. From this point of view, there is a possibility that the quality of the EIS perception varies according to the practitioners working position. With this background in mind, we also tried to find answers for the following question - to what extent does the practitioners working position influence their perception of EIS quality?

\section{Methodology}

An extensive national survey was conducted from July to September 2012 to reveal information from practitioners from four sectors: governmental agencies (governmental sector), local self-governments, private sector, and academic sector (researchers). The main data collection was carried out by online survey - email distributed questionnaires - using Google docs technology.

The questionnaire was sent to more than 450 different representatives (who were later separated into categories, based on working position):

- Participants of the international EIA/SEA conference, which was held in Slovakia during May 2012

- EIA/ SEA licensed experts 
- Specialists in the nature and landscape protection

- Employees of the Ministry of Environment of Slovakia

- Researchers / academic scientists

- Employees of State Nature Conservancy of Slovakia

- Individual representatives of regional and local environmental authorities

From more than 450 sent questionnaires, approximately 130 questionnaires were sent to nonfunctional e-mail addresses, mainly to regional and local environmental authorities.

The survey was completed by 109 people: 47 respondents from governmental sector $(43.10 \%)$, 47 respondents from private sector $(43.10 \%), 9$ respondents from academic sector $(8.30 \%), 1$ $(0.90 \%)$ respondent from local self-government and by $5(4.60 \%)$ respondents who classified their working sector as "other". Because of the really low local-self government's participation, for the purpose of this paper we decided to not consider these results.

The questions asked of the respondents addressed 3 main groups of information:

\section{Basic information}

- Respondent's relations to the EIS

- Respondents and their working sector

- Length of EIA/SEA practice (duration in years)

2. Quality of consultant's qualification

- Quality of consultant's qualification as a negative factor influencing the overall quality of EIS

3. The EIS quality

- Quality of EIS in general;

- Strengths and weaknesses of existing EISs;

- Determination of main problems in processing high-quality EISs

\section{Results}

As noted above, we distinguished for the analyses only three categories - governmental sector respondents (GA) $(43.10 \%)$, private sector respondents (PS) $(43.10 \%)$ and academic sector respondents (AS) (8.3\%). The categories 'other' and 'local-self government' are not considered in this paper because there were only few respondents.

We found out that more than $70 \%$ of our respondents are dealing with EISs within the frame of their everyday working responsibilities and other almost $20 \%$ are EIA consultants. So we can say that our respondents are well experienced in this field of study and their knowledge about EIS quality can be considered more than appropriate.

As results have shown almost one half of all respondents have more than 15 years working experience with the EIA process $(44.10 \%)$ and next $20.3 \%$ of respondents are working in the EIA/SEA sector between $10-15$ years. From the fact, that more than $60 \%$ of our respondents are working in the EIA/SEA sector for approximately more than 10 years, we came to the conclusion that results obtained by our research have high strength and meaningful value.

EIA professionals in general (almost $80 \%$ ) judged the Slovak EISs related to Natura 2000 sites to be generally good/average (Fig. 1). Only few respondents assumed this documentation as an excellent or as a poor.

Overall the quality is clearly considered as good/average by all professional categories (GS $79.92 \%$, PS $-80.95 \%$, AS $-62.50 \%$ ), so there is no difference in quality perception of EISS between selected categories.

In next step respondents were asked if they assume "quality of consultant's qualification" as appropriate / inappropriate - and if not - whether it is one of reasons negative influencing the quality of EISs related to Natura 2000 sites. The average results showed, that respondents mainly do not consider "quality of consultant's qualification" as an appropriate (40.34\%), and again, there is no difference in opinions between selected categories (all of them assumed "quality of consultant's qualification" mostly as inappropriate). Almost $40 \%$ of respondents in general maintained neutral opinion in case of asked the question if "inappropriate quality of consultant's qualification" is seen as an impact which can negatively influence the quality of EISs. 


\section{VERSIT $\Lambda$}

However, there are differences in opinions between categories. While GA (56.52 \%) considered this factor mostly as a neutral, PS (35.29 \%) and mainly AS (66.67 \%) agreed, that "insufficient quality of consultant's qualification" has negative influence on the overall quality of the EIS's related to Natura 2000 sites.

The questionnaire had one open-ended question. Respondents were asked where they see strengths and weaknesses of EIS related to Natura 2000 sites.

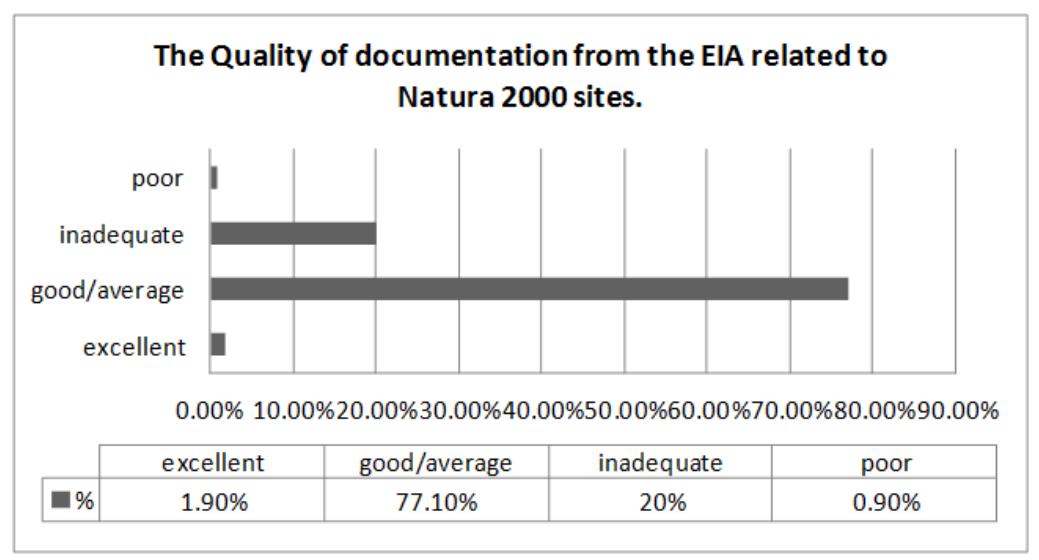

Fig. 1: The quality of documentation from the EIA related to Natura 2000 sites in general - practitioners perception.

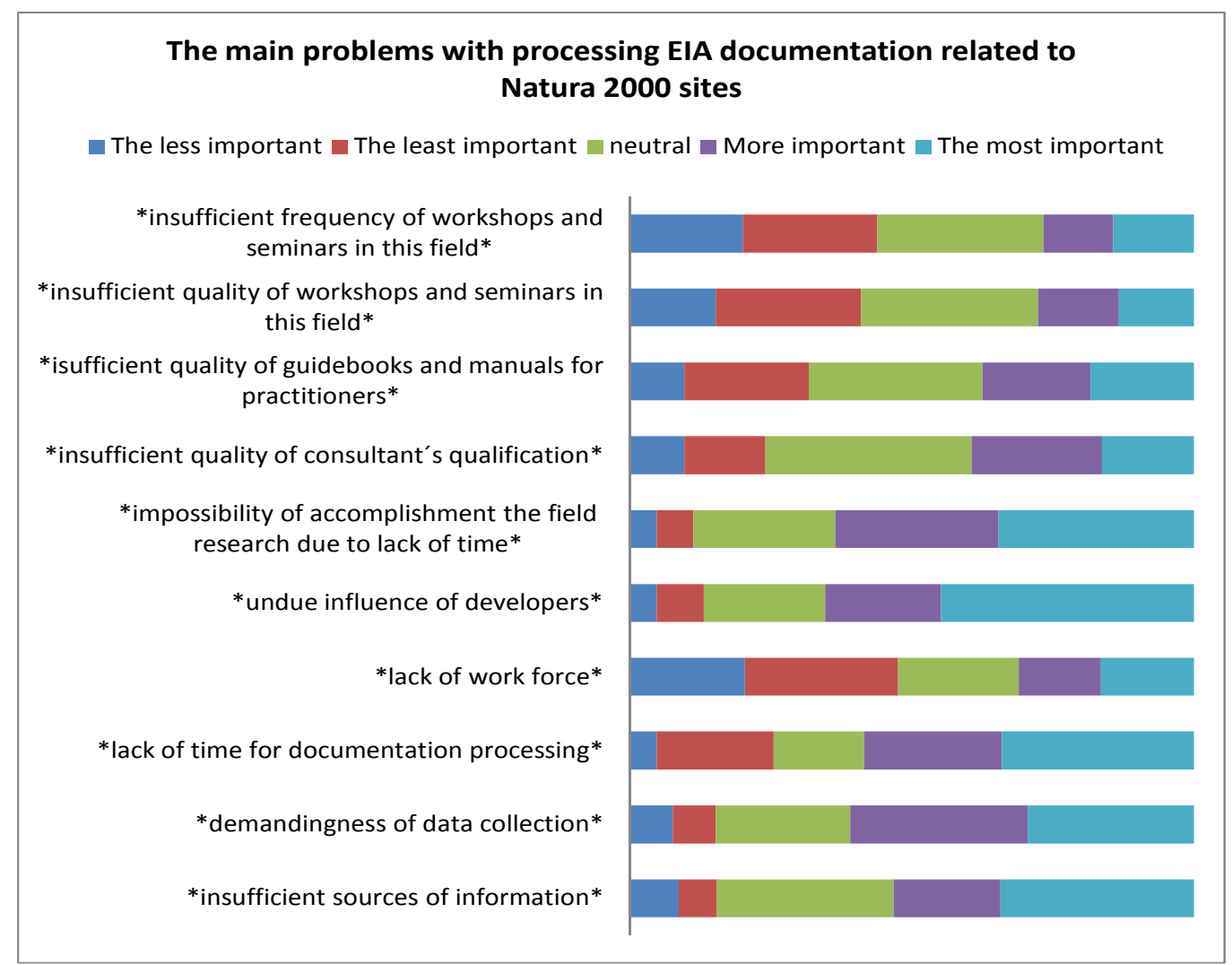

Fig. 2: Grading the main problems for processing good EIS (related to Natura 2000 sites) by Respondents

The most frequent strengths identified by respondents were the facts (in case that AA has to be done - if there is a possibility of significant negative effects on Natura 2000 sites): important habitats have to be mapped, protection for species and habitats with European importance 
should be maintained, proposal of management plans for these sites should be done, lot of useful data are accumulated (easier data accessibility), negative impacts on Natura 2000 sites have to be identified and of course, there is a necessity to comply with the EU terms. Some respondents highlighted that strength is alone the fact that this type of documentation has to be done.

The most frequent weaknesses identified by respondents were following facts: absent data about Natura 2000 sites and often absent management plans, insufficiently mapped habitats, insufficient quality of consultants qualification, decision making based often on finances and on behalf of financial groups and politicians, missing evaluating methodology (evaluation based on subjective perspective), lack of time (etc. for the field research due to developers influence) and work force, as well as problems with property rights.

In the next question, respondents were asked to assign the scale $1-5$ (from the least important to the most important) to identify 10 problems, which could occur during EIS preparation and which could cause its worse quality (Fig. 2).

Tab. 1 - Grading the main problems for processing quality EIS (related to Natura 2000 sites) by respondents percentage proportion

\begin{tabular}{|c|c|c|c|c|c|}
\hline Type of problems (values in \%) & $\begin{array}{l}\text { the less } \\
\text { important }\end{array}$ & $\begin{array}{l}\text { least } \\
\text { important }\end{array}$ & neutral & $\begin{array}{l}\text { more } \\
\text { important }\end{array}$ & $\begin{array}{l}\text { the most } \\
\text { important }\end{array}$ \\
\hline insufficient sources of information & 8,60 & 6,70 & 31,40 & 19,00 & 34,30 \\
\hline $\begin{array}{l}\text { demandingness of data collection } \\
\text { lack of time for documentation }\end{array}$ & 7,60 & 7,60 & 23,80 & 31,40 & 29,50 \\
\hline processing & 4,70 & 20,80 & 16,00 & 24,50 & 34,00 \\
\hline lack of work force & 20,40 & 27,20 & 21,40 & 14,60 & 16,50 \\
\hline $\begin{array}{l}\text { undue influence of developers } \\
\text { impossibility of accomplishment the }\end{array}$ & 4,70 & 8,40 & 21,50 & 20,60 & 44,90 \\
\hline $\begin{array}{l}\text { field research due to lack of time } \\
\text { insufficient quality of consultant's }\end{array}$ & 4,70 & 6,50 & 25,20 & 29,00 & 34,60 \\
\hline $\begin{array}{l}\text { qualification } \\
\text { insufficient quality of guidebooks and }\end{array}$ & 9,60 & 14,40 & 36,50 & 23,10 & 16,30 \\
\hline $\begin{array}{l}\text { manuals for practitioners } \\
\text { insufficient quality of workshops and }\end{array}$ & 9,60 & 22,10 & 30,80 & 19,20 & 18,30 \\
\hline $\begin{array}{l}\text { seminars in this field } \\
\text { insufficient frequency of workshops }\end{array}$ & 15,20 & 25,70 & 31,40 & 14,30 & 13,30 \\
\hline and seminars in this field & 20,00 & 23,80 & 29,50 & 12,40 & 14,30 \\
\hline
\end{tabular}

As we can clearly see from the Fig. 2, in general, respondents seem to consider as the biggest problem during EIS preparation the "undue influence of developers", since almost half of respondents (44.90\%; Tab. 1, yellow color) assumed this problem as the most important.

The next three biggest problems: "impossibility of accomplishment the field research due to lack of time" (34.60\%), "insufficient sources of information" (34.30\%) and "lack of time for documentation processing" (34\%), were identified as the most important (Tab. 1, blue color) by almost the same number of respondents.

The "insufficient quality of consultant's qualification" was assumed from more important problem (23.10\%) up to neutral (36.5\%), which corresponds with results from the previous question, as mentioned above, where respondents in general considered "insufficient quality of consultants qualification" as a neutral problem during EIS preparation. The rest of problems were assumed as a neutral or less important, exact values are stated in Tab. 1. 
From overall results (Tab. 2) we can clearly see, that there were differences between selected groups in the perception of EIS problems.

The average results seemed to show that PS ( $36.5 \%)$ and AS (50.00\%) considered "insufficient sources of information" to be more important problem than GS did. GS tend to see this problem mostly as neutral.

There is no essential difference in perception of the few problems by our selected categories "demandingness of data collection" which is assumed mainly as more or the most important problem by all of the categories (mostly by AS) and which we can consider as one of the biggest problems, and "lack of work force" which is mainly assumed as less important by GS and PS, and as a neutral by AS.

The problem "lack of time for documentation processing" is evaluated differently. While GS and AS tend to see it as more and the most important problem, PS assumed it mostly as least important. The difference can be explained at least partially with different working habits for these groups. Since EIS formation is the main scope of employment for respondents from PS, they should have more time for its formation as respondents from GS and AS - who by contrast use to have a lot of administrative work.

Tab. 2 - Grading the main problems for processing good EIS (related to Natura 2000), based on different perception of three selected categories of respondents - percentage proportion. Explanation: 1 - the less important, 2 - least important, 3 - neutral, 4 - more important, 5 - the most important GS - Governmental sector, PS - Private sector, AS - Academic sector.

\begin{tabular}{|c|c|c|c|c|c|c|}
\hline (all values in \%) & & 1 & 2 & 3 & 4 & 5 \\
\hline \multirow{3}{*}{ insufficient sources of information } & GS & 5,0 & 7,5 & 40,0 & 17,5 & 30,0 \\
\hline & PS & 9,1 & 2,3 & 31,8 & 20,5 & 36,4 \\
\hline & AS & 0,0 & 0,0 & 12,5 & 37,5 & 50,0 \\
\hline \multirow{3}{*}{ demandingness of data collection } & GS & 7,5 & 7,5 & 27,5 & 27,5 & 30,0 \\
\hline & PS & 11,4 & 4,5 & 25,0 & 29,5 & 29,5 \\
\hline & AS & 0,0 & 12,5 & 0,0 & 50,0 & 37,5 \\
\hline \multirow{3}{*}{ lack of time for documentation processing } & GS & 2,6 & 7,9 & 28,9 & 28,9 & 31,6 \\
\hline & PS & 4,7 & 32,6 & 23,3 & 18,6 & 20,9 \\
\hline & AS & 0,0 & 12,5 & 12,5 & 50,0 & 25,0 \\
\hline \multirow{3}{*}{ lack of work force } & GS & 10,0 & 30,0 & 10,0 & 22,5 & 27,5 \\
\hline & PS & 26,2 & 28,6 & 23,8 & 9,5 & 11,9 \\
\hline & AS & 12,5 & 25,0 & 62,5 & 0,0 & 0,0 \\
\hline \multirow{3}{*}{ undue influence of developers } & GS & 0,0 & 2,4 & 21,4 & 28,6 & 47,6 \\
\hline & PS & 11,4 & 13,6 & 20,5 & 13,6 & 40,9 \\
\hline & AS & 0,0 & 12,5 & 12,5 & 37,5 & 37,5 \\
\hline \multirow{3}{*}{$\begin{array}{l}\text { impossibility of accomplishment the field } \\
\text { research due to lack of time }\end{array}$} & GS & 4,8 & 4,8 & 28,6 & 28,6 & 33,3 \\
\hline & PS & 6,8 & 9,1 & 27,3 & 22,7 & 34,1 \\
\hline & AS & 0,0 & 0,0 & 12,5 & 50,0 & 37,5 \\
\hline \multirow{3}{*}{ insufficient practitioners competency } & GS & 10,0 & 17,5 & 30,0 & 27,5 & 15,0 \\
\hline & PS & 11,6 & 18,6 & 25,6 & 25,6 & 18,6 \\
\hline & AS & 0,0 & 0,0 & 87,5 & 0,0 & 12,5 \\
\hline \multirow{3}{*}{$\begin{array}{l}\text { insufficient quality of guidebooks and } \\
\text { manuals for practitioners }\end{array}$} & GS & 5,0 & 22,5 & 37,5 & 15,0 & 20,0 \\
\hline & PS & 11,6 & 25,6 & 25,6 & 16,3 & 20,9 \\
\hline & AS & 12,5 & 25,0 & 25,0 & 25,0 & 12,5 \\
\hline \multirow{3}{*}{$\begin{array}{l}\text { insufficient quality of workshops and } \\
\text { seminars in this field }\end{array}$} & GS & 9,8 & 29,3 & 31,7 & 17,1 & 12,2 \\
\hline & PS & 18,6 & 27,9 & 18,6 & 14,0 & 20,9 \\
\hline & AS & 12,5 & 25,0 & 37,5 & 25,0 & 0,0 \\
\hline \multirow{3}{*}{$\begin{array}{l}\text { insufficient frequency of workshops and } \\
\text { seminars in this field }\end{array}$} & GS & 9,8 & 22,0 & 39,0 & 17,1 & 12,2 \\
\hline & PS & 27,9 & 25,6 & 14,0 & 9,3 & 23,3 \\
\hline & AS & 12,5 & 25,0 & 50,0 & 12,5 & 0,0 \\
\hline
\end{tabular}


Overall, as mentioned above, respondents indicated the "undue influence of developers" as the biggest problem - GS by $47.6 \%$ and PS by $40.9 \%$. AS tend to see it as the more important problem (37.5 \%) up to the most important problem (37.5\%).

The second most important problem is "impossibility of accomplishment field research due to lack of time" which all of groups graded mainly as the more important up to the most important. Here, it should be taken into consideration that this problem is especially in case of EIS related to the Natura 2000 sites (with all its species and habitats with special type of protection) very important. Besides, when we take into account the problem "undue influence of developers" as the most important problem identified by all of respondents we can say that these two problems are in many times coherent that the problem "impossibility of accomplishment the field research due to lack of time" can be caused just because of "undue influence of developers".

In addition we found out that there is a contrast in results from academic sector related to the problem "insufficient quality of consultant's qualification". This problem is assumed by AS mostly as a neutral factor (87.5\%), but on the other side - as mentioned above - they also agreed (66.67 \%) that "insufficient quality of consultant's qualification" is the impact with negative influence on the overall quality of the EIS's related to Natura 2000 sites.

The following factors were considered as less important up to neutral problems : "insufficient quality of guidebooks and manuals for practitioners", "insufficient quality of workshops and seminars in this field" and " insufficient frequency of workshops and seminars in this field". The perception of these problems is in accordance within all of the categories.

\section{Discussion}

Practitioner perceptions have been the subject of a number of studies. For example, many of them have been done in Western Australia since 2000. Morrison-Saunders and Bailey (2003) investigated practitioner perceptions of the scientific basis of impact assessment in Western Australia, and to a certain extent contrasted the perceptions of the four main groups: proponents, consultants, EIA regulators, and other government agencies.

More recent is the study of Morgan et al. (2012), a national survey which was conducted among existing impact assessment practitioners, with the purpose of eliciting differences in perspectives about the impact assessment process, and relating it to the professional allegiance, education and training of the respondents. Jalava et al. (2010) conducted a survey among EIA professionals, covering consultants and competent authorities, as to their opinion about the quality of EIS in Finland. There is also similar type of research in Western Australia, which examined practitioner's perceptions of biodiversity in EIA (Wegner et al. 2005).

The most comparable research is an earlier study (Morrison-Saunders et al. 2001), which concerned practitioner perspectives on what "drives" the EIA quality; and what role science plays in the production of quality EIS documentation. Participants were asked how they would define a "good" EIS, whether they believed that proponents are under pressure to produce the good EIS. There were 21 sources of pressure on proponents to produce good EISs identified by participants, the most commonly cited was from regulators (61\%) - all types of EIA practitioner identified this source. The most cited pressures, which participants tend to see as pressures affect the quality of the EIS, according to Morrison-Saunders et al. (2001), were amount of time (52\%) and money (43\%). Although we did not use the same methodology, the most important problems identified by our research are similar to Morisson-Saunders et al. (2001).

\section{Conclusions}

This research has helped to identify the main problems for developing a high quality EIS (related to Natura 2000 sites). Identification of these problems was the first step on the way for the consequential minimalization and later elimination of these problems.

The findings reported in this paper showed that there are differences in perception and identification of the most important problems for 
developing high quality EIS (related to Natura 2000 sites) between selected groups (governmental sector, private sector, academic sector).

The overall results seemed to show that respondents assumed the quality of EISs in Slovakia as generally good / average.

According to obtained data we have specified the three biggest problems. All respondents assumed the "undue influence of developers" as the most important problem for developing high quality EIS (related to Natura 2000 sites).

The second most important problem is "impossibility of accomplishment the field research due to lack of time", which is really important especially for EIS related to Natura 2000 sites and which in many times can be coherent with "undue influence of developers".

The third biggest problem identified by all of our groups is "demandingness of data collection".

The findings of presently running research mainly focused on representatives from the regional and local environmental authorities will supply current results after research finalization. Research results will also be supplemented by results from interviews with selected representatives, which are planned for the end of November 2012. On the base of determined results, the set of measures for problems elimination will be proposed.

\section{Acknowledgements}

This research was supported by the Grant UK No. UK/485/2012 - Selected Questions from Issues of Environmental Impact Assessment forcefully on Natura 2000 sites - the Practitioners Perspective.

\section{References}

Jalava K, Pasanen S, Saalasti M, Kuitunen M (2010) Quality of environmental impact assessment: Finish EISs and the opinions of EIA professionals. Impact Assessment and Project Appraisals 28: 1527.

Morgan RK, Hart A, Freeman C, Coutts B, Colwill D, Hughes A (2012) Practitioners, professional cultures, and perceptions of impact assessment. Environmental Impact Assessment Review 32: 1124.
Morrison-Saunders A., Annandale D., Cappelluti J. (2001): Practitioner perspective on what influences EIA quality. Impact Assessment and Project Appraisal 19(4): 321-325.

Morrison-Saunders A., Bailey J. (2003): Practitioner perspectives on the role of science in environmental impact assessment. Environmental Management 31: 683-695.

Ortolano L., Sheperd A. (1995): Environmental impact assessment: challenges and opportunities. Impact Assessment 13: 3-30.

Pavličková K, Kozová M, Chrenščová V, Petríková D, Pauditšová E, Moravčíková Z (2009a) Environmentálne plánovanie a manažment, Univerzita Komenského v Bratislave, Prírodovedecká fakulta, Učebnica, Bratislava.

Pavličková $K$, Kozová $M$, Miklošovičová $A$, Žarnovičan $H$, Barančok P, Luciak M (2009b) Posudzovanie vplyvov na životné prostredie: Vysokoškolský učebný text [CD/ROM]. Univerzita Komenského, Bratislava.

Pinho P, Maia R, Monterroso A (2007) The quality of Portuguese Environmental Impact Studies: The Case of Small Hydro Power Projects. Environmental Impact Assessment Review 25: 189-205.

Pölönen I, Hokkanen P, Jalava K (2011) The effectiveness of the Finish EIA system - What Works, what doesn't, and what could be improved? Environmental Impact Assessment Review 31: 120-128.

Samarakoon M, Rowan JS (2008) A critical review of environmental impact statements in Sri Lanka with particular reference to Ecological Impact Assessment. Journal of Environmental management 41: 441-460.

Snell T, Cowell R (2006) Scoping in environmental impact assessment: balancing precaution and efficiency? Environmental Impact Assessment Review 26: 359-376.

Toro J, Requena I, Zamorano M (2010) Environmental impact assessment in Colombia: Critical analysis and proposals for improvement. Environmental Impact Assessment Review 30: 247-260.

Wegner A, Moore SA, Bailey J (2005) Consideration of biodiversity in environmental impact assessment in Western Australia: practitioner perceptions. Environmental Impact Assessment 25: 143-162.

Wood C (2003) Environmental Impact Assessment - A Comparative Review, second edition. Pearson Education Ltd. Edinburgh Gate. 